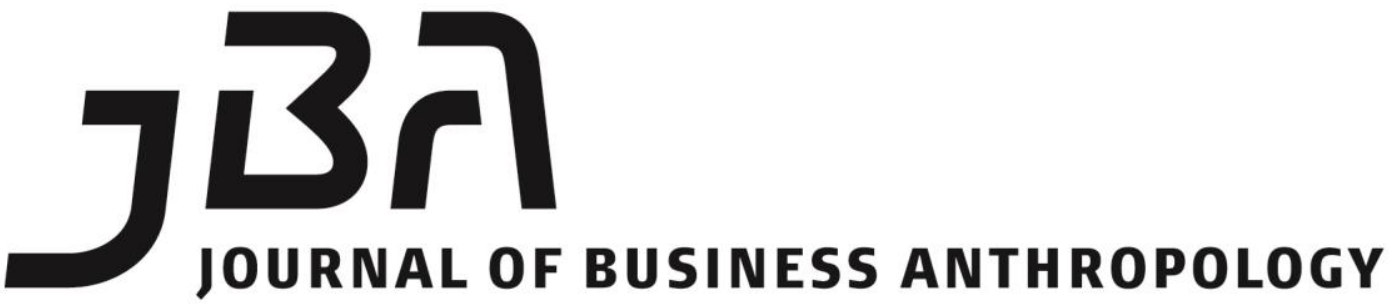

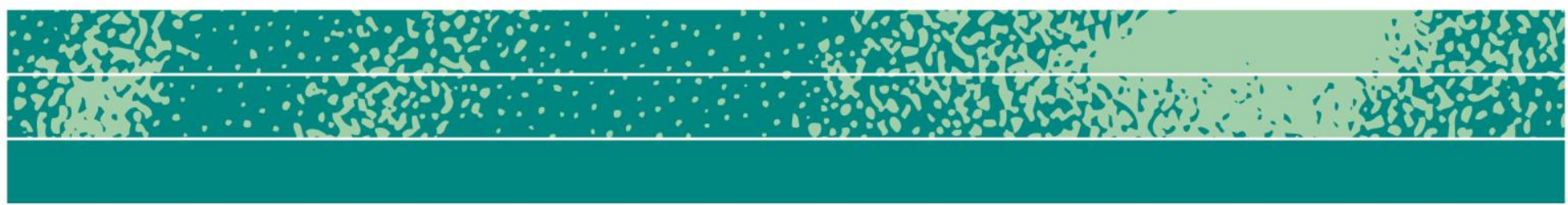

\section{Ethical Considerations in Global Multi-Stakeholder Work Contexts}

\author{
Julia C. Gluesing
}

\begin{abstract}
Economic integration and globalization has brought increasing ethical complexity into business anthropology as more anthropologists work in or research multinational enterprises that cross multiple boundaries. Ethical challenges arise from the predominant neoliberal viewpoint in these enterprises, the embeddedness of ethics in culture, and from intercultural nature of multi-stakeholder environments. Using an example of one research project in an MNE, this article illustrates the ethical challenges of the MNE work context and how these challenges can be resolved and discusses current ethical dilemmas and the future implications for the growth and practice of business and organizational anthropology.
\end{abstract}

\section{Keywords}

Globalization, ethical complexity, neoliberalism, multinationals, multistakeholder environments
Page 1 of 17

JBA Special Issue 1: 79-95, Spring 2014

(C) The Author(s) 2014 ISSN 2245-4217

www.cbs.dk/jba 


\section{Introduction}

As the processes of economic integration and globalization have accelerated remarkably over the past twenty years, multinational enterprises (MNEs) stand at the center of trade, investment and the transfer of knowledge and technology. Everyday, MNEs cross many boundaries on multiple levels: political, legal, and economic boundaries at the national, regional and community level, various external and internal organizational boundaries, the boundaries of language, and multiple cultural boundaries - all of which must be recognized, negotiated, and integrated in some way to get work done on a global scale (Leung et al. 2005). Since the 1990s, anthropologists have been writing about and investigating MNEs as the primary vehicles for the movement of information, symbols, capital, and commodities in global and transnational spaces (Appadurai 1996). For business and organizational anthropologists the complex global arenas of MNEs mean that there are multiple stakeholders in any research project that crosses global work contexts, creating ethical complexity. This article is about one global research project, called ATI, which illustrates from a business anthropologist's first-hand experience and perspective the reasons for and challenges of ethical complexity in the MNE multi-stakeholder work context and discusses how the multidisciplinary research team addressed these challenges. The example concludes with a discussion of current ethical dilemmas and their implications for the future of anthropological work in, and study of, business and organization in global MNE multistakeholder work contexts.

\section{The ethical challenges of complex global business}

There are three primary reasons why MNEs create an ethical complexity that poses challenges for business and organizational anthropologists: (1) there is a perspective of neoliberalism in MNEs that generates the prevalent ethical principles for decision making; (2) ethical judgments are embedded in culture and are especially difficult to grasp when multiple cultural arenas are involved; and (3) ethical conduct in MNEs is also an intercultural phenomenon that requires negotiation across cultural boundaries.

The first reason for ethical complexity is the predominance in MNEs of the neoliberal perspective. Neoliberalism is based in the belief that freely adopted market mechanisms are the optimal way of organizing all exchanges of goods and services, and includes the conviction that the only legitimate purpose of the state is to safeguard individual, especially commercial, liberty, as well as strong private property rights (Hayek 1979; Bourdieu 1998; Friedman 2006). The neoliberal perspective is a difficult one for anthropologists to sort out, because neoliberalism incorporates many concepts that anthropologists might agree with, such as the active creation of social and economic order. But it is also 
universalist in its advocacy for a corporate form of agency, in which people should see themselves in a means-end relationship with the world, and see themselves as though they were a business (Gershon 2011: 539). MNEs develop codes of ethics, especially ethical principles for decision making, from two main schools of thought based in formalism and utilitarianism: rules and results (Jackson 2007). Ethics in business has generally meant rules about how the company and its employees should act internally, and toward consumers and others in the marketplace because of what is "right" or simply because of what is required by law. These rules are usually made by management and are generally meant to apply corporate-wide, across the MNE. However, recently, the Code of Ethics is shifting somewhat from a universally "right" and "wrong" basis for action to one that emphasizes sustainability, such that what is ethical is that which produces a sustainable operating environment, whether it is social, economic, political, or environmental, or even all of these in combination. Ethics is becoming intertwined with operational sustainability, or results:

The New Ethics is a conduct of business that enables a company to optimize its returns to shareholders, employees, customers, business partners, local communities, and the environment. It is a dynamic standard for pursuing profitability and growth that allows future generations an equal opportunity for growth and development.

(Laszlo and Nash 2007:2)

The challenge for anthropologists in the prevalence of neoliberalism and this shift to sustainability is the very dominant and dynamic nature of this view of ethics. For researchers, the "New Ethics" means that within the MNEs people's views, especially managerial decision-makers, are likely to be changing in adaptation to the current global and local business environment. Ethics becomes a moving target.

The second reason MNEs create ethical complexity is the relationship of culture and ethics itself and the many cultural arenas that are likely to be involved in any research to be conducted in MNEs. There is general agreement among sociologists and anthropologists that ethical ideas, beliefs, views, or judgments and the practices that accompany them derive from general social practices and accords, or to say it another way, are "socially constructed" (Abend 2008). Why particular groups of people have the moral views that they do, and what the effects of these views are on behavior, interaction, structure, change, and institutions is a dominant topic of ethnographic work. What makes it so challenging in the context of MNEs is the sheer number of groups with whom one must become acquainted, at least superficially, in order to sort out the ethical viewpoints that must be managed to conduct a research project.

Thirdly, the process of globalization, with MNEs as drivers of this 
process, can be understood as the intensification of exchange, both economic and social, across national borders (Scherer and Patzer 2011). This process increases the number of interactions of people and organizations from different cultural and national backgrounds. Ethics becomes intercultural in nature and anthropologists who want to do research in MNEs can find themselves in the challenging position of having to negotiate ethics within the MNE as well as among stakeholders outside the MNEs, such as universities and funding agencies, whose views might and do conflict with one another. Not only do anthropologists have to try to understand the different ethical standards and viewpoints of multiple stakeholders, but they also have to become the negotiators for reconciliation of these multiple ethical standards if research is to go forward.

\section{Ethical complexity in the ATI research project}

The story of a United States National Science Foundation (NSF) funded research grant called "Accelerating the Diffusion of Innovations: A Digital Diffusion Dashboard Methodology for Global Networked Organizations,"1 provides a very real illustration of the ethical complexity in multinational enterprises, and is a good example for a discussion of the ethical dilemmas anthropologists face in conducting research, especially in interdisciplinary research teams with multiple stakeholders.

\section{Background}

The idea for the research project came about when my colleagues (from the academic disciplines of information systems, communication, and engineering) and I had been consulting and teaching in the automotive industry for over a decade. We had observed that, despite the increasing ubiquity and sophistication of information technology (IT), organizations were not taking advantage of the capabilities inherent in their information infrastructure to manage their global innovation processes and networks. We thought that the information technology infrastructure could be used to investigate the diffusion of innovation in multinational corporations, which are global networked organizations. We believed that a company could use its IT infrastructure not only to create, transmit and store communication messages, but also to learn something about how the innovation of new technology was proceeding across the company's global product development network. These ideas formed the basis for our NSF proposal to develop a new methodology for investigating and leveraging a company's IT infrastructure to accelerate the diffusion of an innovation. We proposed to develop IT-based methods by tapping into the company's infrastructure and to validate our methods using ethnography. The NSF funded the grant for three years beginning in 2005,

${ }^{1}$ http://www.nsf.gov/awardsearch/showAward.do?AwardNumber $=0527487$ 
and the grant received a two-year extension to continue the research until 2010 .

The Digital Diffusion Dashboard (DDD) NSF grant focused on one automotive innovation with several sub component systems, which had the pseudonym Advanced Technology Innovation (ATI) to comply with corporate confidentiality requirements (which will be discussed later in this article as part of the ethical issues faced by the researchers). The ATI product innovation was not a top-down mandatory component built into a vehicle, for example, like a safety belt or an air bag. Rather, ATI was a bottom-up innovation, which was shaped and reshaped by a team of specialized engineers from different disciplines to determine its system compatibility, and its final functional features for customer appeal and competitive advantage. An auto product development innovation team must persuade members of the social system targeted for adoption - such as engineers who specialize in the engine, transmission, chassis, and electrical subsystems for a new vehicle program - of the value of adopting its new technology, and how it will meet or exceed anticipated user needs, as well as satisfy the requirements for engineering cost, timing, weight, performance, safety and regulatory specifications for inclusion on a vehicle.

The adoption or rejection of such innovations can be a long, difficult and arduous path - especially when the team is globally distributed taking anywhere from three to five years from idea to production in a vehicle that is ready for marketplace introduction. Using IT-based methods, we designed and tested a set of indicators, which we assembled into a prototype "Digital Diffusion Dashboard" (DDD) to help innovation managers visualize, monitor, and manage their global innovations and accelerate innovation in a global networked organization. We created simple, clear, and reusable dashboard indicators that we thought would help open a new frontier for both scholars and practitioners alike by demonstrating how to leverage a company's data resources - primarily email - to visually manage the diffusion network as it emerges, and to monitor the consequences of implementation efforts during the diffusion process. The indicators made visible the ATI Team's network of interactions, the main topics of their conversation, and how they felt about their work over time. ATI managers linked the indicators to their own business performance metrics to get an overall sense of how the innovation diffusion process was proceeding.

The multiplicity of stakeholders: study teams, corporate, and government stakeholders

Automotive product development is most certainly a complex multistakeholder research context. The research involved the following primary stakeholders who all had their own views about ethics and ethical behavior: two collaborating study teams, corporate management, 
including the legal staff and human resource departments, the study participants themselves (the ATI product development innovation team), the university institutional review boards (IRBs), and the governmental funding agency, the NSF. The research team also referenced the American Anthropological Association (AAA) Code of Ethics in considering and making decisions about ethical issues during the course of the research.

The two teams who collaborated to conduct the NSF DDD study were the university-based researchers and the internal corporate research team. The university team included two other professors and me as the principal investigators on the grant, plus graduate and undergraduate research assistants. We led the study and were responsible for the study design, software choice, indicator selection, all research approvals, and for training the internal research team how to install and use the software for the study. We were also the people who had to negotiate our way through the difficult ethical landscape. The internal corporate research team consisted of five company engineers who managed the internal corporate IT resources, databases, and security for the study. This team also performed the dashboard testing and indicator validation, and facilitated access to research subjects and settings for the ethnographic research. The members served as internal technical experts regarding the product development process and as liaisons to the university research team.

On the corporate side, the primary stakeholders were corporate management, the legal staff and the human resource departments. The spokespersons for corporate management were the seven people who reported to the chairman as global vice presidents. They assumed the overall corporate oversight and support for the research and had very practical ethical criteria for evaluating the outcomes. Their motivation for participating as an industry partner for an NSF study was to gain access to leading edge university research. By providing in-kind resources in the form of managerial and employee time, as well as use of company facilities and equipment, they hoped to receive tools that might give them a competitive advantage. The legal staff got involved in the research to review and ensure the protection of the MNE's intellectual property and employee privacy rights, and in the implementation of regulatory compliance for the conduct of research across the multiple national locations. The human resources department was primarily concerned with protecting employee privacy rights and obtaining permissions for the research from employees.

The Global ATI Team members were the study participants, and consisted of 298 people distributed in locations around the world. This team was charged with navigating the innovation through the global product development process, obtaining buy-in from the component vehicle engineers, and persuading a target program team to adopt their innovation and include it in the vehicle that would eventually be 
produced and sold in the marketplace.

There were two university institutional review boards that had to give their approvals for the research to begin and move forward. Both of these review boards had their own systems for evaluating the research and for ensuring compliance with both university and U.S. federal government requirements.

The NSF Human and Social Dynamics program itself, which funded the study, was the last primary stakeholder. Their interest was ensuring the study would contribute to the broader societal and public good, as well as advance graduate and undergraduate education and training.

Because the research project involved anthropologists, who were responsible for investigating the "whys and hows" behind the innovation process and validating the IT-based dashboard metrics with "ground truth", the AAA Code of Ethics was the guiding reference for ethical decisions on the research team, especially when the decisions concerned human subjects. The engineers and IT specialists on the university and corporate research teams were most concerned with IT security and intellectual property protections.

The complexity presented by multiple stakeholders in the NSF research project resulted in ethical challenges throughout the five-year study, requiring that the university research team learn the ethical viewpoints of each of the primary stakeholders and serve as negotiators across the various group.

\section{Ethical challenges}

The general neoliberal perspective of the corporate stakeholders in the MNE meant that ethics was reviewed according to market criteria that ensured competitive advantage and minimized the impact of governmental regulations. Ethical considerations included keeping all data gathered in the research inside the corporate IT firewall and minimizing the potential of leaks that might occur in giving "outsiders", the university research team and the NSF, access to confidential company information, especially information about a high-stakes innovation that was under development. The NSF also embodied some of the same free market concerns by seeking to ensure national advantage in the marketplace through funding of research in the corporate sector with an eye to fostering a faster development cycle of ideas to products in the nation overall, but, at the same time, the agency actively promoted by advocating a policy of open sharing of data from the research with other researchers both inside and outside the U.S. In fact, one of the elements of the NSF research proposal was the development of a database of descriptive information about innovations and their diffusion trajectories, which could be accessed and used by other researchers for future studies. There was an ethical challenge presented by the corporate desire to 
protect its innovations, and the NSF focus on openness and sharing of research results. Was it ethical to share corporate data, or not?

The protection of human subjects was another ethical challenge for the university research team. The MNE legal staff and the human resource staff were in agreement about protecting the privacy of the MNE's employees. However, the human resources rules and regulations were different in all the countries where the ATI project was ongoing. That meant that the human resources policies in each country had to be reviewed and repaired, and legal negotiations had to be undertaken. The NSF had one set of rules, based on U.S. governmental regulations regarding human subjects research, and these rules were in turn incorporated into the IRBs at the two universities as a requirement for government funding, but with different implementation practices in each. The IRBs did agree that the IT-based data gathering could be conducted, as long as no participant could be identified. The ethnographic data would have to be subjected to the approvals process for behavioral data at both universities, however.

The research team had to contend with contradictory recruitment policies regarding research participation in each country as well. The recruitment policies in MNE locations around the world varied and were often contradictory. For example, in the U.S. the policy was one of general informed consent with employees agreeing to participate in the research with the option to "opt out" at any time. In Germany, however, it was just the opposite: employees were actively required to "opt in" to the research individually after the German Workers Council had approved the research project.

Over and above the general protection of human subjects, employees had their own personal safety and privacy concerns, which posed a challenge to both the university and the corporate research teams. The IT-based data collection methods involved the automated gathering of employee email, a sensitive matter indeed. As far as corporate management was concerned, the MNE owned all employee email and could access it and read it at any time. All employees, when they logged onto the corporate intranet, saw an automatic message saying that their email was company property and not their own and by logging on they acknowledge that fact. However, from the perspective of the employees, their email was still private, and they did not want "just anybody" accessing it and reading it, let alone analyzing it. Human resource policies also supported this position, regardless of the corporate legal position. Therefore, the university research team was faced with the task of convincing employees that their individual email would not be read by either of the two research teams, internal or university, or by anyone outside the company. The researchers gathered 45,000 emails to create the Digital Diffusion Dashboard, and their links among more than 2,000 people across the enterprise communicating about the ATI 
innovation project over time. The DDD metrics were designed to answer seven important evaluative questions that a manager might want to know about an innovation:

1. Who Is Talking?

Who is talking about the innovation?

What group of the company do they represent?

What level of the company is talking about the innovation?

2. Who Are the Champions?

Who is central in the network?

3. How Is the Team Collaborating?

Who is involved in the network?

Are the right people talking?

Is anyone missing?

4. What Is the "Buzz" about the Innovation?

What are people saying about the innovation?

5. What Is the Emotion of the Team?

Are people talking positively or negatively about the innovation?

6. What Is the Rate of Adoption?

Is the innovation diffusing fast enough?

Is it spreading throughout the organization as it should?

7. What Is the Value Proposition?

What is the value of the innovation to the organization?

While corporate management, human resources staff, legal counsel, and the universities' IRB boards considered much of this information sensitive and confidential, it was the participants themselves who especially expressed concern because their individual reputations and careers could be at risk. Ethical concerns also arose for everyone because the participants' email boxes contained email sent, forwarded, or copied from people who may not have consented to participate in the study.

\section{Resolving the ethical challenges}

To respect the MNE's desire for data security and protection of intellectual property and the NSF's desire for open data sharing, the university research team, in collaboration with the internal research team, agreed to keep the "raw data" inside the corporate firewall. This restriction meant that the researchers could create a database or publication that contained only the results of the study. The data leading to the results had to stay with the company. This decision specified that the researchers could not continue to analyze data after the conclusion of the study because they would not have access to it, and it meant that the NSF could receive and share results but would not have the promised database of descriptive data about the innovation. It also meant that the researchers could not call the MNE or the innovation by their real names 
but would have to use pseudonyms. The decision was an unusual compromise for the researchers who are accustomed to keeping the data they collect, but it applied only to the IT-based data.

The ethnographic data were another story. The anthropologists successfully presented their case to the MNE, to the university IRBs, and to the study participants for protecting and preserving their data, and not giving anyone inside or outside the corporation access to it. The AAA Code of Ethics ${ }^{2}$ was instrumental in supporting the argument.

Human subjects, participant recruitment, personal safety, and privacy concerns surrounding the collection of email data, were all resolved by establishing four procedures with the support of the IT staff and through clear and honest communication with study participants, with approvals from corporate legal and human resources staff around the globe and the university IRBs:

1. All ATI team members received an emailed consent form, approved by the IRB, which they returned with their consent or refusal to participate, which meant that everyone had to actively choose to "opt in". Team members who elected to participate in the study could also "opt out" at any time.

2. The research teams did not gather all email, only the email that was related to the ATI innovation project. To collect only this subset of email, the ATI Team members participating in the study installed and activated email rules themselves (which again meant they had to actively choose to participate), using common project keywords (emic language). They copied their email, using a "dummy" email address in the "cc" field, to a centralized, secure server email box with restricted access. They could readily see the dummy email address in their email header and delete it if they did not wish to have a particular email sent to the dummy mailbox in the secure server.

3. Two additional filters were placed in the rules. First, if an email was designated as personal, private, or encrypted, it was automatically excluded from data collection. Second, all legal email around patents that was labeled as "privileged" was excluded from data collection.

4. The university team could not read any individual email. All email content was aggregated as frequency counts for single words or word pairs for analysis. No email message could be reconstructed.

\footnotetext{
2 The AAA code of ethics contains the following major guidelines:

- Do no harm.

- Be open and honest regarding your work.

- Obtain informed consent and necessary permissions.

- Weigh competing ethical obligations due collaborators and affected parties.

- Make your results accessible.

- Protect and preserve your records.

- Maintain respectful and ethical professional relationships.
} 
Email was also anonymized for any public presentation, for example, user 1 , user 2 , user 3 . After some deliberation, the University IRB and the company's human resource staff decided that because all the email was anonymized for analysis and no individual email could be reconstructed, there was no violation of confidentiality or privacy ethics from their points of view.

The anthropologists on the research team did know who many of the participants were because they talked with them about the ATI innovation project and shadowed them in their work, in accordance with informed consent and with all corporate and IRB approvals of data collection protocols. However, the ethnographers were not able to connect any of the emails with the ethnographic data without the participants giving the anthropologists permission to look at their specific email. The anthropologists did not remove email data from the work site, not just because of both personal privacy and corporate security reasons, but also out of respect for participants in the study. The anthropologists wanted to encourage trust in the research team and between the team and participants.

It took about eight months to resolve the challenges posed by the ethical complexity in the multi-stakeholder context of the ATI research project, and was especially difficult for the anthropologists on the team, who were leading this aspect of the project. ${ }^{3}$ The project could not get started without negotiated agreements based on the various rules and regulations of the various agencies, governments, and the MNE's corporate legalities and policies. However, there were ongoing ethical decisions that had to be made as new challenges arose throughout the project. The anthropologists had to develop an approach to ethics that could serve as a reference for the project team, as they encountered these challenges and worked toward their resolution throughout the life of the project. What follows is an extended discussion of this approach and the dilemmas that are before all anthropologists who do this work.

\section{Discussion and ongoing ethical dilemmas}

All of the actions the stakeholders negotiated to resolve ethical issues involved both complying with rules and regulations (which include ethical considerations, but cannot be equated with ethics) and considering the ethical decisions to be made within the specific circumstances of the work context. The anthropologists on the research team were the ultimate decision-makers in the project, primarily because they considered not only what was right by law and by rule, but also what

\footnotetext{
${ }^{3}$ In another MNE that was part of the same National Science Foundation grant, it took two years to negotiate intellectual property rights, involving the research team (especially the anthropologists who did not want to disclose interview data), corporate managers and legal staff in different countries, and both universities' legal staff.
} 
was ethical according to their own ethical values, the values of the people with whom they were working, and the values of the people they were studying. In other words, the anthropologists practiced what could be called situated and relational ethics, taking a pragmatic approach grounded in what they considered to be good anthropology.

In business anthropology, research is generally conducted in the context of daily organization work, where the ethics of everyday activities are often ambiguous. Therefore, a practical and situated ethics helps clarify ethical reasoning in the course of normal problems, or ethical dilemmas that workers and managers face in doing their jobs (Alvesson and Svenningsson 2003). Explicit ethical codes espoused by organizational leaders and those who are part of formal organizational policy in an MNE, as well as the formal Code of Ethics adopted by the American Anthropological Association, are of some value as guidelines. However, ethical judgments that are made as part of everyday work are emergent and practical. Ethics are embedded in the situated, particular realities of a context in all its complexity, especially in MNEs where multiple boundaries are crossed and different, often divergent, values and ways of understanding and working are likely to intersect.

To negotiate the ethical complexity in the ATI research project, the anthropologists had to use practical wisdom. In the Nicomachean Ethics, Aristole (1999) outlines three types of intellectual virtual: Episteme, Techne, and Phronesis. Episteme is known as scientific knowledge (also called declarative knowledge, or know-what) and is considered to be universal and relatively context independent. Techne, known as craft knowledge or technical art (also called procedural knowledge, or knowhow), is dependent on context, but oriented toward the production of something pragmatic. Phronesis is practical wisdom. It is "concerned with action about things that are good or bad for a human being" (Aristotle 1999: 89). Phronesis has an ethical component. It is not the "right" way of doing things as might be specified by rules and regulations, or laws in a particular community, but the ethically good action a practical, wise person would take. Phronesis puts practice in the foreground and closely connects ethics and action in situated circumstances, since it is "concerned with action and action is about particulars" (Aristotle 1999: 92).

In the ATI project, ethical evaluations were situated and contextualized and discussed by the research teams, both internal and external, and communicated to other stakeholders, and perhaps even negotiated and modified based on stakeholder feedback. However, these evaluations did not mean "anything goes" in a relativist sense. Some universals, such as "do no harm" or "be open and honest regarding your work" in the AAA Code of Ethics were strong points of reference to guide behavior. However, anthropologists, and other stakeholders, too, made ethical judgments and decisions based on the business, technical, and 
social context, which presented limited choices and possibilities for action. The identification and evaluation of ethical or unethical behavior was based on what was occurring in a specific situation within a particular context in the course of the ATI project's everyday work activities and the research activities involved. Phronesis guided the anthropologists, and the other stakeholders as well, through the particularities of contextual complexity

Phronesis is developed through experience and cannot be taught as part of a university curriculum. It is gained by sharing situations, cases and stories, and is achieved through discussion with members of different kinds of organizations and who might hold different points of view. The anthropologists working on the ATI project had to practice their trade in the MNE, and reflect and talk about their work in general (without reference to confidential information) with other anthropologists and those outside the discipline in the workplace and on research teams.

Socialization and training must occur in practice, in an emergent way, in order for business anthropologists to develop phronesis, and to create an ethical community of practice. As Nyberg (2008: 596) has so rightly stated:

Giving people time to reflect upon and discuss their activities does not necessarily change them but it does make change more likely. The alternative is to enforce disciplinary and controlling pressures to make people behave in certain ways. However, rules or principles will not get us there, since we cannot expect people to act ethically if there they are given no opportunity to exercise practical ethical judgement. This is the major point: following ethical codes does not involve choice, merely compliance; if one does not choose to act, one has not acted ethically.

There will always be situations that codes of ethics cannot cover. In the complexity of life in an MNE, "universal" rules can only take one so far and one cannot know or memorize them all. Rules may even restrict the capacity to act ethically. It is the practical wisdom to handle particular situations that anthropologists wishing to work in or study complex, global multi-stakeholder organizational contexts must develop over time through practice. For academics who train anthropologists, the development of practical wisdom means that students have to be given the opportunity to practice in complex organizational settings under the guidance of experienced business anthropologists. There also must be an opportunity to reflect within the larger community of practice, and this generally takes place at conferences such as the Ethnographic Praxis in Industry (EPIC). This reflection is important for students, but it is equally and especially important for business anthropologists who are already practicing in MNEs or other large complex organizations. 
Doing "good anthropology" means tracking between the universal and the local, and between general and specific knowledge, "wherein specificity of insight lends credibility to general knowledge, and local knowledge holds the grains of universal wisdom" (Gershon 2011: 550). Good anthropology also means resisting the neoliberal perspective that tends to group together people, communities, or even nations in terms of business or market skills, treating them as though they were all alike, as corporate forms. Gershon (2011) has advocated an "Ethics of Imagination," in which anthropologists pay attention to social forms of organization, to epistemological differences, and to relationships with people as individuals. The ATI researchers attempted to make ethical decisions based on a consideration of how people were related to one another in their organizational networks, both formal and informal social networks, and on an understanding of how people might be personally affected by the decisions, and the multiple ways they might view the situation and the decisions. This took time, which ultimately limited the scope of the research. However, acting within a central tenant of care, in which the researchers valued and respected the connection between themselves and the people they studied, was both a "practical" and "good" anthropology in this author's opinion.

Phronesis as the basis of good anthropology is processual in nature as well as experiential and relational. Complex global work is and will continue to be rapidly changing, so there will be no wisdom that is "once and for all". As our working landscape becomes ever more digital and distributed, and we are faced with new ethical dilemmas posed by the internet, as well as yet unforeseen technological and societal developments, as practicing business anthropologists we must develop a "discourse ethics" (Palazzo and Sherer 2006; Sherer and Patzer 2011). Discourse that includes storytelling and reflection fosters continual discussion of the situations encountered, and how best to act with wisdom where ethical dilemmas are posed and ethical decisions are required. In an almost postnational era of globalization, the complexity of our dynamic multi-stakeholder business environment requires an open and continual discourse to maintain practical wisdom in the face of the ethical challenges anthropologists face now and will face in the future. Such a discourse ethics is both a constructivist and an intercultural philosophy of ethics that encourages both relativistic and universalistic debate of ongoing situated action that leads to practical knowledge consistent with Aristotle's concept of phronesis.

\section{Conclusion}

This article highlights the three primary reasons for ethical complexity in multi-stakeholder work contexts: (1) the predominance of neoliberal thinking; (2) the difficulty of dealing with ethics that are culturally embedded and that also cross multiple boundaries at multiple levels; and 
(3) the intercultural nature of most interactions in these enterprises that necessitate continual negotiation. The example of the global ATI project provides an illustration of the ethical challenges that result from this complexity and how these challenges were resolved through eight months of negotiation. The ATI researchers considered the rules, regulations, policies, and laws in the MNE, universities, funding agencies, and various codes of ethics to reach ethical decisions over the life of the project. Which research practices are considered ethical, and in particular, what data - including corporate data - it is ethical to protect or consider confidential, is a matter of compromise across multiple views of ethics and is based in an attuned consideration of context. Acquiring local knowledge and basing decisions in a system of "common sense" (Geertz 1983: 73-93) worked for the team to resolve ethical dilemmas as they faced them.

Doing "good anthropology" and making "good ethical decisions" clearly involves more than expertise in international law or the rules and regulations or formal policies of international business. Ethics in business anthropology is based on an understanding of context, in the ability of the anthropologist to dig deep to surface and learn about people's perspectives and their reasoning, and how it is situated in particular contexts. Ethics is about relationships and social organization, and about how people refer to the universal in making ethical decisions, while also paying attention to the particularities and constraints of the situation to know not only the right thing to do, but also the good thing to do in the circumstances under a tenant of care. As business and anthropology moves more and more into the global business arena, it will be increasingly important to teach and to learn through practical experience, reflection, and discourse, if we are to make wise ethical decisions in our own work, as it changes and adapts over time to new circumstances.

\section{References}

Abend, Gabriel. 2008. Two main problems in the sociology of morality. Theory and Society 37:87-125.

Alvesson, Matts and S. Svenningsson. 2003. Managers Doing Leadership: The Extra-Ordinarization of the Mundane. Human Relations 56(12):14351459.

Appadurai, Arjun. 1996. Modernity at Large: Cultural Dimensions of Globalization. Minneapolis: University of Minnesota Press.

Aristotle. 1999. Nicomachean Ethics, T. Irwin, trans. $2^{\text {nd }}$ Edition. Indianapolis: Hackett.

Bourdieu, Pierre. 1998. L'essence du néolibéralisme: Le Monde 
diplomatique Mars 1998. http://www.mondediplomatique.fr/1998/03/BOURDIEU/10167

Friedman, Thomas. 2006. The World is Flat: The Globalized World in the Twenty-First Century. London: Penguin.

Geertz, Clifford. 1983. Local Knowledge. New York: Basic Books.

Gershon, Ilana. 2011. Neoliberal agency. Current Anthropology 52:537555.

Hayek, Friedrich A. 1979. Law, Legislation and Liberty: A new Statement of the Liberal Principles and Political Economy. Volume III: The Political Order of a Free People. London: Routledge.

Jackson, T. 2007. Cross-cultural sensitivities in developing corporate ethical strategies and practices. In Corporate Ethics and Corporate Governance, W. Zimmerli, K. Richter and M. Holizinger, eds., pp. 229-250. Berlin: Springer.

Leung, K., with R. Bhagat, N. Buchan, M. Erez, and C. Gibson. 2005. Culture and international business. Journal of International Business Studies 36:357-378.

Laszlo, Christopher and Jeremy Nash. 2007. Six facets of ethical leadership: An executive's guide to the new ethics in business. Electronic Journal of Business Ethics and Organization Studies 12(2):1-7.

Nyberg, Daniel. 2008. The Morality of Everyday Activities: Not the Right, but the Good Thing to Do. Journal of Business Ethics 81:587-598.

Palazzo, Guido and Andreas Georg Scherer. 2006. Corporate legitimacy as deliberation: A communicative framework. Journal of Business Ethics 66:71-88.

Scherer, Andreas Georg and Moritz Patzer. 2011. Beyond universalism and relativism: Habermas's contribution to discourse ethics and its implications for intercultural ethics and organization theory. In Philosophy and Organization Theory, Research in the Sociology of Organizations, Vol. 32, H. Tsoukas and R. Chia, eds., pp. 155-180. Emerald Group Publishing Limited. 
Julia Gluesing is a business and organizational anthropologist and Research Professor in Industrial and Systems Engineering at Wayne State University, where she teaches global perspectives in engineering management, global leadership, and qualitative research methods course in the Global Executive Track Ph.D. She was the Principal Investigator on a National Science Foundation Grant, the "Digital Diffusion Dashboard," to study the diffusion of innovation across the global enterprise by tapping into an organization's the information technology infrastructure. She has published professionally, most recently as an editor and contributing author of Mobile Work Mobile Lives: Cultural Accounts of Lived Experiences (Blackwell 2008), and a contributing author in Virtual Teams that Work: Creating Conditions for Virtual Team Effectiveness (Jossey-Bass 2003), Handbook of Managing Global Complexity (Blackwell 2003), and Crossing Cultures: Lessons from Master Teachers (Routledge 2004). Julia also is President of Cultural Connections, Inc., a research, consulting and education firm supporting global business development. She can be reached at j.gluesing@wayne.edu 